\title{
EOSINOPHILIC PLEUROPERICARDIAL EFFUSION DUE TO VALPROIC ACID
}

\author{
Fatma ŞiMȘEK ${ }^{1 *}$, Nazım KIZILDAĞ ${ }^{2}$ \\ ${ }^{1}$ Atatürk University, Faculty of Medicine, Department of Neurology, 25240, Erzurum, Turkey \\ ${ }^{2}$ District training and Research Hospital, Department of Neurology, 25240, Erzurum, Turkey
}

\begin{abstract}
Valproic acid is widely used in the treatment of many diseases. It has common side effects such as nausea, vomiting, diarrhea, dizziness, tremor, hair loss, thrombocytopenia. Valproic acid can rarely cause eosinophilic pleuropericardial effusion. Case report; a 31-year-old male patient who had been using valproic acid since childhood due to epilepsy presented with respiratory distress. Eosinophilic pleuropericardial effusion was detected in the examinations performed in the patient with progressive respiratory distress. After excluding other etiological causes, this condition is assumed to be related to valproic acid. Drug changes were made. The end of six months, was observed to be completely cured. Conclusion: This adverse is generally thought to result from drug hypersensitivity reaction. But it is seen that it is an important factor in drug dosage.
\end{abstract}

Keywords: Valproic acid, Pleuropericardial effusion, Epilepsy, Eosinophilia

*Corresponding author: Atatürk University, Faculty of Medicine, Department of Neurology, 25240, Erzurum, Turkey

E mail: klamaks@hotmail.com (F. ȘiMȘEK)

$\begin{array}{llll}\text { Fatma ȘiMŞEK } & \text { (iD) https://orcid.org/0000-0003-1662-5534 } & \text { Received: April 30, 2021 }\end{array}$

Nazım KIZILDAĞ (iD) https://orcid.org/0000-0003-1655-5695

Accepted: December 01, 2021

Published: January 01, 2022

Cite as: Şimşek F, Kızıldağ N. 2022. Eosinophilic pleuropericardial effusion due to valproic acid. BSJ Health Sci, 5(1): 104-106.

\section{Introduction}

Valproic acid (VPA) is one of the commonly used agents in the treatment of many diseases such as epilepsy, migraine, bipolar disorder. Common side effects of VPA include nausea, vomiting, diarrhea, dizziness, tremor, hair loss, thrombocytopenia. VPA-related eosinophilic pleural effusion is one of the very rare side effects reported previously (Bally et al., 2011; Rubins and Rubins, 1996). Pleural effusion due to VPA toxicity can be unilateral or bilateral. Eosinophilic pleural effusion is a pleural effusion containing at least $10 \%$ eosinophils (Adelman et al., 1984; Kalomenidis and Light, 2003). Although most cases are idiopathic in eosinophilic pleural effusion, malignancy, pneumothorax, infection, pulmonary embolism, pancreatitis, heart failure, drug reactions are among the causes (Kalomenidis and Light, 2003). In drug-induced pleural effusion, symptoms usually begin to improve within the first few days after discontinuation of the drug, and the pleural effusion resolves completely within a few months (Huggins and Sahn, 2004). We present a case that has been using VPA for a long time and has a bilateral eosinophilic pleuropericardial effusion that occurs after dose increase.

\section{Case Report}

A 31-year-old male patient with epilepsy was evaluated due to shortness of breath. There was a shortness of breath that had been around for 10 days and progressively progressed. The patient has been using VPA since the age of 9 for epilepsy. 6 months ago, the drug dose was gradually increased from $1000 \mathrm{mg}$ to $2000 \mathrm{mg} /$ day. Levetiresetam $2000 \mathrm{mg} /$ day was added to his treatment for 3 years. He had no other known illnesses and drug use. His blood pressure was 110/80 $\mathrm{mmHg}$, heart rate was 71 beats / min, breathing rate was 30 minutes and body temperature was $36.8{ }^{\circ} \mathrm{C}$. On examination, bilateral lung sounds were not natural, there were no additional cardiac sounds and murmurs. Neurological examination was normal. Her electrocardiography was in normal sinus rhythm. On the chest $x$-ray and thorax tomography, the image was compatible with bilateral pleural effusion (Figure 1).

Her transthoracic echocardiogram (ECO) had minimal effusion in front of the right ventricle. In blood tests, on the hemogram; hemoglobin was $10.6 \mathrm{~g} / \mathrm{dL}$, white blood 8230 cells/ $\mu \mathrm{L}$ (neutrophil 56.7\%, monocyte 16.1\%, eosinophil 1\%, basophil 0.3\%). Biochemistry test results; creatinine was $0.7 \mathrm{mg} / \mathrm{dL}$, blood urea nitrogen 12.62 $\mathrm{mg} / \mathrm{dL}$, aspartate aminotransferase $30 \mathrm{U} / \mathrm{L}$, alanine aminotransferase $11 \mathrm{U} / \mathrm{L}$, albumin $3.25 \mathrm{~g} / \mathrm{dL}$. Thyroid hormone levels were normal. VPA drug blood level was $143 \mu \mathrm{g} / \mathrm{mL}$ (therapeutic range 50-100 $\mu \mathrm{g} / \mathrm{mL}$ ). Pericardiocentesis and thoracentesis were performed in the patient whose respiratory distress continued to progress. Liquid exudative fluid was discharged from thoracentesis by $1000 \mathrm{cc}$ from the left thorax and $750 \mathrm{cc}$ by pericardiocentesis. Pleuropericardial fluid analysis revealed $65 \%$ eosinophils. Histopathological examination of $\mathrm{E}$ fusion was evaluated as an eosinophilic material. In thorax tomography, lung parenchyma was normal and 
there was no evidence of pulmonary embolism. There were no parasitic infections. In the patient with high VPA drug blood level, it was thought that pleuropericardial effusion was due to drug toxicity. The patient's VPA treatment was reduced and discontinued. To the treatment for seizures, lacosamide was added and gradually increased to $400 \mathrm{mg} /$ day. The clinical and radiological findings of the patient completely improved after 6 months.
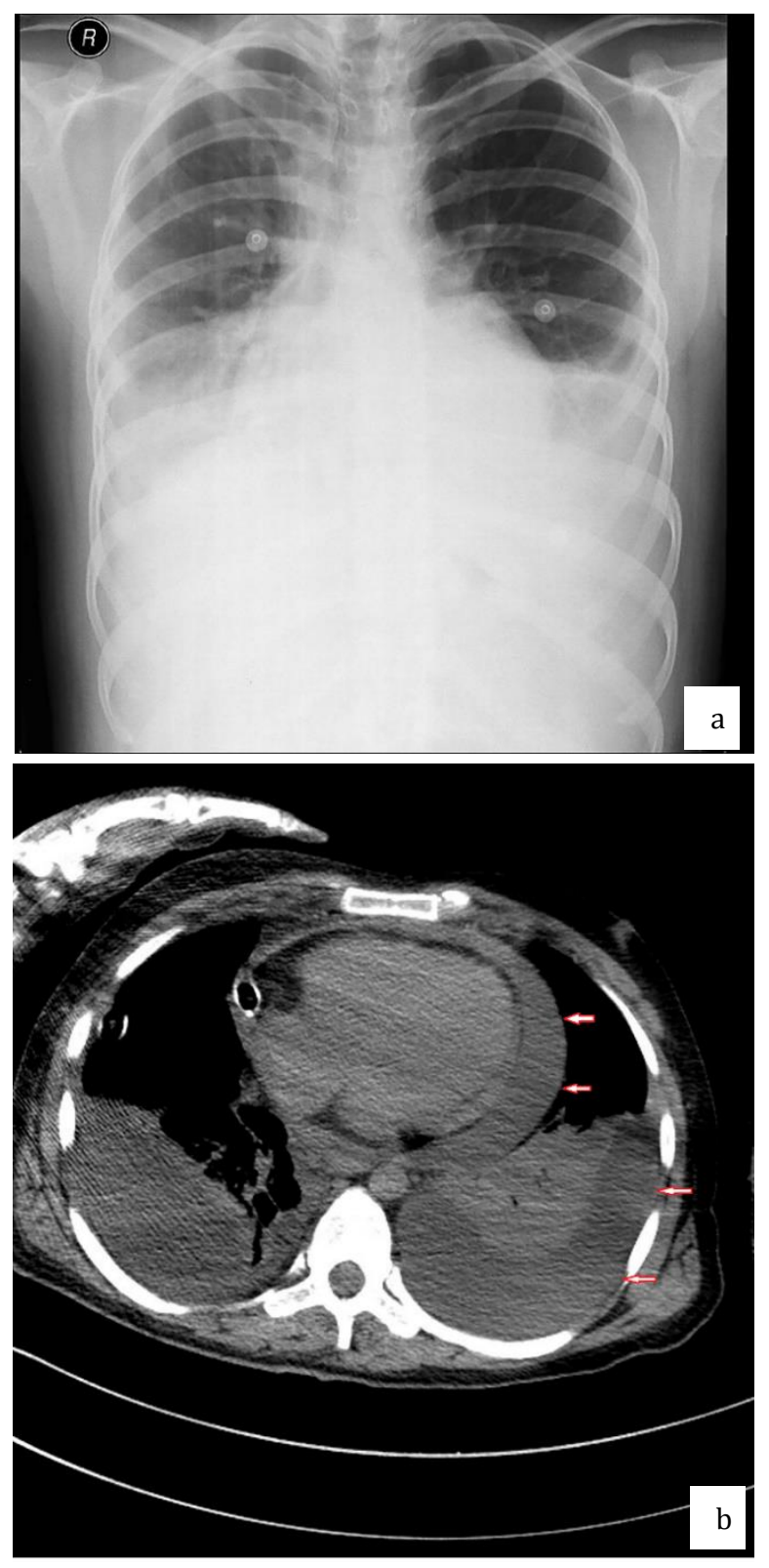

Figure 1. Chest x-ray shows bilateral pleural effusion (a), thorax tomography shows pleural fluid in right-left hemithorax and pericardial fluid in pericardium (b).

\section{Discussion}

Acyclovir, bromocriptine, fluoxetine, dantrolen, infliximab, VPA are rarely drugs that can cause eosinophilic pleural effusion. The delay time between exposure to the first drug and the development of eosinophilia in the pleural fluid is typically several months, but this can range from a few days to 1-2 years or even 12 years (Heidecker et al., 2006; Huggins and Sahn, 2004). The mechanism of action for pleural eosinophilia due to valproic acid is unknown; however, 1) acute hypersensitivity reaction, 2) dose-related direct toxic effect, 3) drug-related inflammation of the pleural cavity, and 4) oxidant-induced mesothelial cell damage are among the possible mechanisms (Antony, 1998). While our patient has been using VPA since childhood, the level of the drug was increased to $2000 \mathrm{mg} /$ day 6 months ago, and the blood level of the drug was 143 $\mu \mathrm{g} / \mathrm{mL}$ (therapeutic range $50-100 \mu \mathrm{g} / \mathrm{mL}$ ) in the examinations performed while it was being followed up due to respiratory distress, suggesting the direct toxic effect of the drug. This is evidence that drug-related pleural effusion is important not only in the acute hypersensitivity reaction but in the drug dose.

In our patient, the eosinophil rate was $1 \%$ in the peripheral blood examination, while the eosinophil rate was $65 \%$ in the pleuropericardial fluid examination. Laboratory analysis of peripheral blood is generally not specific in patients with eosinophilia in the pleural fluid because there is only a weak correlation between the percentages of eosinophils in peripheral blood and the pleural fluid (Krenke et al., 2009).

The patient had an image compatible with pleuropericardial effusion on ECO and thorax tomography. In the literature, it is stated that most cases related to valproate have only pleural effusion and these effusions are either eosinophilic or lymphocytic (André et al., 2005; Kaufman and O'Shaughnessy, 1995). VPAinduced pericardial effusion is a rare condition and it should be considered in drug toxicity.

As a result; VPA-induced pleuropericardial effusion is a rare condition and drug dosage is also effective in its occurrence apart from drug hypersensitivity reaction. Follow-up with the drug blood level during drug dose increase may prevent the occurrence of rare side effects.

\section{Author Contributions}

All authors had equal contribution and reviewed and approved the manuscript.

\section{Conflict of Interest}

The author declared that there is no conflict of interest.

\section{Ethical Approval/Informed Consent}

Written an informed consent form was obtained from the patient for the case presentation and necessary information was given to the family.

\section{References}

Adelman M, Albelda SM, Gottlieb J, Haponik EF. 1984 Diagnostic utility of pleural fluid eosinophilia. The American J Med, 77(5): 915-920.

André S, Drowart A, De Bels D. 2005. Lymphocytic pleural effusion associated with valproic acid. European J Inter Med, 16(7): 535.

Antony VB. 1998. Drug-induced pleural disease. Clinics in chest 
Med, 19(2): 331-340.

Bally C, Martin C, Kraoua S, Kanaan R, Lacronique J, Dusser D, Burgel P. 2011. Eosinophilic pleural effusion related to taking valproic acid. Revue de Pneum Clin, 67(6): 363.

Heidecker J, Kaplan A, Sahn SA. 2006. Pleural fluid and peripheral eosinophilia from hemothorax: Hypothesis of the pathogenesis of EPE in hemothorax and pneumothorax. The American J Med Sci, 332(3): 148-152.

Huggins JT, Sahn SA. 2004. Drug-induced pleural disease. Clinics in Chest Med, 25(1): 141-153.

Kalomenidis I, Light RW. 2003. Eosinophilic pleural effusions.
Current Opin Pulmon Med, 9(4): 254-260.

Kaufman J, O'Shaughnessy IM. 1995. Eosinophilic pleural effusion associated with valproic acid administration. Southern Med J, 88(8): 881-882.

Krenke R, Nasilowski J, Korczynski P, Gorska K, Przybylowski T, Chazan R, Light RW. 2009. Incidence and aetiology of eosinophilic pleural effusion. European Respir J, 34(5): 11111117.

Rubins JB, Rubins HB. 1996. Etiology and prognostic significance of eosinophilic pleural effusions: a prospective study. Chest, 110(5): 1271-1274. 